International Conference on Ceramics, Bikaner, India

International Journal of Modern Physics: Conference Series

Vol. 22 (2013) 729-732

(C) World Scientific Publishing Company

DOI: $10.1142 /$ S2010194513010933

\title{
FACTORS THAT AFFECT THE LUNG DEPOSITION
}

\author{
Ms SHWETA SANKHALA \\ Research Scholar, Department of Physics, Jai Narain Vyas University \\ Jodhpur, Rajasthan, India \\ shwetalodha21@gmail.com \\ Dr. H. S. SINGH \\ Department of Physics, Jai Narain Vyas University \\ Jodhpur, Rajasthan, India \\ Dr. S. K. SINGH \\ Department of Civil Engineering, Jai Narain Vyas University \\ Jodhpur, Rajasthan,India \\ Dr. GAUTAM LALWANI \\ Department of Chemical Engineering, Jai Narain Vyas University \\ Jodhpur, Rajasthan, India
}

\begin{abstract}
The lung is an external organ forming the site of unwanted material or particles. In order to protect it, the airways have to be highly effective filters and if the particle deposit they need to be cleared. Inhaled particles can cause a variety of diseases. There are various factors on which the prediction of depositing particles depends, such as age, particle size, flow rate gender, the physics of the particles, the anatomy of the respiratory tract etc.
\end{abstract}

Keywords: Impaction, Sedimentation, Diffusion.

\section{Introduction}

Breathing is the most essential job of life. Breathing stops life stops. Once air progresses through nose or mouth, it travels through, the larynx, the trachea and a progressively subdividing system of bronchi and bronchioles until it finally reaches the alveoli where the gas exchange of carbon dioxide and oxygen takes place, thus air has a long way to go.

But with air certain particles get inhaled which enters the respiratory tract and even enters into the blood stream, consecutively the effects are produced. Example benezene when inhaled metabolizes in both the liver and the bone marrow producing damage in central nervous system an hematopoietic tissue. Besides this these inhaled particles ${ }^{6}$ a variety of pulmonary diseases such as asthma, Chronic Obstructive Pulmonary disease, Chronic Bronchitis, Emphysema etc. The number of such patients suffering has risen sharply over past few years alarming for research so that optimal drug delivery can be given. In human beings particles ranging from $1 \mu \mathrm{m}$ to $10 \mu \mathrm{m}$ can deposit easily thus 
following questions are always needed to be answered as: how much particle is deposited, how much is absorbed by the blood, what about redistribution and storage , how much is removed ,cleared excreted; and how much is left to lead harmful effects?

Mathematical and Computational method (already existing) are always required for these answers.

\section{Particle Deposition Mechanisms}

Deposition $^{6}$ means the event of a particle to adhere the surface ${ }^{1}$ (inner walls of lungs). Inhaled particles are deposited in the airways depending on the physical properties such as particle size, breathing pattern, airways geometry, deposition mechanism, age, gender.etc. There are various deposition mechanisms which include IMPACTION, SEDIMENTATION, and DIFFUSION etc.

\section{Various Deposition Models}

As discussed earlier there are various mathematical and computational methods that are used to calculate the deposition fractions, they are:

1. Semi-Empirical Models: Treating human lung as a series of compartment via which air passes and gets filtered the semi-empirical equations are used to calculate deposition fractions.

2. Deterministic or Single Path Models: ${ }^{4,5}$ This model considers lung as a simple branch structure having identical structure dimensions leading each parent airway into two identical daughter airways.

3. Trumpet Model: This model was proposed by $\mathrm{Yu}^{2}$, that uses Weibel's morphometry of the human lungs. Thus treats human lungs as a one dimensional structure where cross-sectional areas vary with depth yielding an envelope function like a trumpet.

4. Computational Fluid Mechanics Based Model: This model considers lung as threedimensional structure. Thus this model considers the lateral and axial airway surface, and using transport equations calculates the deposition amount.

\section{Factors Affecting Deposition}

The basic factors that influence inhaled particle deposition can be categorized as under:

- The physics of the aerosols: The physical and chemical properties of the aerosols such as shape, size, density hygroscopic or hydrophobic character, the forces (flow rate) acting upon it etc.

- The anatomy of the respiratory tract: It includes the diameter, the length and the branching structure, branching angles of airway segments.

- The airway patterns in the lung airways

Physiological factors include airflow and breathing patterns, which influence particle deposition. 


\section{Particle Size as a Major Factor in Deposition}

The experimental and mathematical models indicate that particle size has a vital role in deposition. In general the natural defense mechanism of our body protects and clears the particle which are two large from reaching the alveoli but the medium size particles create the real trouble. The largest particle (generally $>2 \mu \mathrm{m}$ ) deposit due to impaction, which happens when inertia of a particle causes it to deviate from the airstream. Sedimentation impacts particles $0.1 \mu \mathrm{m}-2.5 \mu \mathrm{m}$ in diameter and occurs when gravitational forces acts on particle, making it fall of a slowing airflow onto the airway wall. Particles $<0.1 \mu \mathrm{m}$ in diameter deposit as a result of random collisions with air molecules and air walls by process of Brownian diffusion.

Different subjects were chosen at a sampling station in Jodhpur, using the equations already developed by Cheng et. al. the total deposition fraction and IFVC were calculated.

Table 1. Below is the theoretical calculation of TDF for different age people at a sampling station in Jodhpur.

\begin{tabular}{ccccc}
\hline $\begin{array}{c}\text { Particle size } \\
(\mu \mathrm{m})\end{array}$ & Age & Breathe per minute & $\begin{array}{c}\text { Total deposition } \\
\text { fraction of Men at } \\
\text { the sampling } \\
\text { station }\end{array}$ & $\begin{array}{c}\text { Total deposition } \\
\text { fraction of } \\
\text { Women at } \\
\text { sampling } \\
\text { station }\end{array}$ \\
\hline 0.005 & 27 & 15 & 0.70 & 0.72 \\
\hline 0.050 & 32 & 9 & 0.32 & 0.34 \\
\hline 0.100 & 39 & 20 & 0.19 & 0.21 \\
\hline 0.150 & 29 & 19 & 0.13 & 0.15 \\
\hline 0.200 & 34 & 16 & 0.15 & 0.13 \\
\hline 0.500 & 32 & 20 & 0.13 & 0.13 \\
\hline 1 & 38 & 15 & 0.12 & 0.12 \\
\hline 3 & 26 & 20 & 0.30 & 0.44 \\
\hline 5 & 29 & 18 & 0.56 & 0.69 \\
\hline
\end{tabular}

Thus the total deposition fraction value indicates the effect of particle size, showing that it increases with increasing particle size. In the trachea bronchial region particles deposit most efficiently at diameters of almost $1 \mu \mathrm{m}$ or greater besides which there is a strong monotonic relation between size and deposition. Due to this Many obstructive diseases affect the small alveoli but there are a limited number of clinical studies that have tried to study deposition in, and clearance.

\section{References}

1. Weiel ER. The morphometry of the human lung. New York: Academic Press 1963.

2. Yu CP. Exact analysis of aerosol deposition during steady breathing. Powder Technol. 1978; 21:55-62. 
3. Singh S.K., Chowdhary G.R., Purohit Gopal, "Assessment of impact of high particulate concentration on peak expiratory flow rate of lugs of sand stone Quarry workers", International journal of Environmental research and Public health 2006, 3(4), 355-359.

4. Yeh HC, Schum GM. Models of human lung airways and their application to inhaled particle deposition. Bull Math Biol. 1980; 42:461-80.

5. Martonen TB. Analytical model of hygroscopic particle behavior in human Airways. Bull Math Biol. 1982; 44:425-42.

6. Hussian, Madl, Khan. "lung deposition predictions....contemporary diseases." The Health 2011; 2(3): 101-107. 